\title{
Identificación de patrones relevantes a la sequía agrícola a partir del análisis espacial y temporal del Índice de Condición de la Vegetación - Caso estudio: Áreas agrícolas de la región Piura, Perú (2000 - 2017)
}

\author{
Gisell Carbajal ${ }^{1}$, Bram Willems ${ }^{1,2}$ y Waldo Lavado ${ }^{3}$ \\ ${ }^{1}$ Facultad de Ciencias Físicas, Universidad Nacional Mayor de San Marcos, Ap. Postal 14-0149, Lima, Perú \\ ${ }^{2}$ Centro de Competencias del Agua, Jr. Bolognesi 150 A, 303, San Miguel, Lima, Perú \\ ${ }^{3}$ Servicio Nacional de Meteorología e Hidrología del Perú, Jr. Cahuide 785 Jesús María, Lima 11 - Perú
}

Recibido el 19 de noviembre del 2018. Revisado el 9 de diciembre del 2018.

Aceptado el 10 de diciembre del 2018

DOI: https://doi.org/10.33017/RevECIPeru2018.0013/

\section{Resumen}

En el presente trabajo se analiza la evolución espacial y temporal del Índice de Condición de la Vegetación (ICV), con el propósito de identificar patrones relevantes a la ocurrencia de eventos de sequía agrícola en Piura. EI ICV provee información acerca del estado de crecimiento de la vegetación durante situaciones extremas, y se deriva del producto: valores del Índice de Vegetación de Diferencia Normalizada (NDVI) - datos del sensor MODIS (Espectrorradiómetro de Imagen de Resolución Moderada) a una resolución espacial de $1 \mathrm{~km}$ en el periodo 2000-2017 a bordo del satélite Terra (MOD13A3, versión 6) obtenida en su paso diurno entre las 10:30 horas y las 12:00 horas (hora local). Los patrones espaciales del ICV revelan que, para el caso de las áreas agrícolas de secano, en el 2004, el $21 \%$ presentaron condiciones de sequía extrema y severa, mientras que en el 2007 fue el 19,5\%, el 2011 el 15,5\% y el 2014 llegó al $21 \%$. Por otro lado, para el caso de las áreas agrícolas por regadío, en el 2004 se vieron afectadas el 44,2 \%, el 2005 fue el 55,4\%, el 2007 fue el 38,8 \%, el 2011 fue el $17,1 \%$ y el 2014 fue el $37,1 \%$.

Descriptores: Sequía, patrones espaciales, áreas agrícolas, secano, regadío, ICV

\section{Abstract}

The present work, the spatial and temporal evolution of the Vegetation Condition Index (VCI) is analyzed, with the purpose of identifying patterns relevant to the occurrence of agricultural drought events in Piura. The $\mathrm{VCl}$ provides information about the growth state of the vegetation during extreme situations, and it is derived from the product: Normalized Difference Vegetation Index (NDVI) values - MODIS (Moderate-Resolution Imaging Spectroradiometer) sensor data at a spatial resolution of $1 \mathrm{~km}$ in the period 2000-2017 on board the Terra satellite (MOD13A3, version 6) Obtained in its passage between 10:30 am and 12:00 pm (local time). The spatial patterns of the $\mathrm{VCl}$ reveal that, in the case of rainfed agricultural areas, in $2004,21 \%$ presented extreme and severe drought conditions, while in 2007 it was $19.5 \%$, in 2011 the $15.5 \%$ and 2014 reached $21 \%$. On the other hand, in the case of irrigated agricultural areas, $44.2 \%$ were affected in $2004,55.4 \%$ in $2005,38.8 \%$ in $2007,17.1 \%$ in 2011 and $37.1 \%$ in 2014.

Keywords: Drought, spatial patterns, agricultural areas, dry land, irrigated land, ICV

\section{Introducción}

La Organización Meteorológica Mundial define la sequía como: "un período de condiciones meteorológicas anormalmente secas, suficientemente prolongado como para que la falta de precipitaciones cause un grave desequilibrio hidrológico" [1]. Sin embargo, Wilhite y Glantz 
definen cuatro tipos de sequía: La sequía meteorológica se define como la ausencia prolongada de precipitación en una región durante un período de tiempo prolongado [2]. La sequía hidrológica es un periodo en el cual los recursos hídricos son insuficientes para satisfacer la demanda de agua de una región. Este tipo de sequía puede demorar-se respecto de las sequías meteorológicas y agrícolas [2]. La sequía agrícola puede definir-se cómo la ausencia de humedad en el suelo, hecho que dificulta la supervivencia de las plantas y cultivos. Debido a la diversidad de plantas y sus respectivas necesidades, resulta difícil establecer un umbral de sequía agrícola para cada región geográfica [2]. La sequía social o económica es la escasez de agua trasladada a las personas y sus actividades económicas. Su aparición se vincula a cualquier sector económico que se vea afectado por dichas circunstancias [2]. La sequía es un fenómeno que tiene su origen en el déficit de precipitaciones y sus impactos se dan en los ámbitos agrícolas, ecológicos y socio- económicos, afectando el bienestar de las poblaciones. Estudios recientes muestran que hay correlación entre la sequía y la reducción de la producción primaria neta (NPP por sus siglas en inglés) a nivel mundial [3].

En el Perú, de los 1729 distritos analizados para el PLANGRACC (Plan Nacional de Gestión del Riesgo de Desastres) a nivel nacional, 1301 distritos tienen riesgo en sequías con diferentes niveles, lo que representa el $75.25 \%$ del total. En el escenario agrícola, la región de Piura está catalogada con riesgo medio [4]. En particular, la sequía ha ocasionado pérdidas considerables, principalmente en las provincias de Morropón, Ayabaca y Huancabamba, $y$, en segundo orden, en las provincias de Piura, Sullana, Sechura, Paita y Talara; durante los años 2003, 2004 y 2005. Ello se tradujo en la pérdida de miles de hectáreas de cultivos instalados o dejadas de instalar; pérdida de hatos de ganado debido a la escasez de pastos y ha propiciado la migración del poblador rural a las ciudades urbano marginales [5]. Según reportes de la Dirección Regional de Agricultura (http://www.regionpiura.gob.pe/documentos/plan_p revencion_desastres_grp.pdf), entre enero y febrero del 2004, se perdieron 9028 ha de cultivos instalados, lo que asciende a pérdidas económicas valorizados en \$23856 301.43. Por su parte, debido a una combinación de sequía y heladas, entre octubre 2004 a febrero 2005, los daños en los cultivos, pastos y ganadería suman $\$ 151$ 882780.5 [5]. Análisis de la serie histórica de producción agrícola del MINAGRI en Piura, revela que los años 2004, 2007, 2011 y 2014 muestran la ocurrencia de eventos de sequía y está correlacionada con pérdidas de hectáreas cultivadas [6].

La sequía es un fenómeno de origen climático (asociado a un déficit prolongado de lluvias) y se considera 4 categorías de sequía: meteorológica, hidrológica, agrícola y socio-económica [7,8,9]. Dichas categorías están correlacionadas y usualmente ocurren de forma secuencial, es decir, una sequía meteorológica prolongada acarrea un déficit en los caudales (sequía hidrológica), lo que, de excederse un nivel determinado, conduce a una pérdida de áreas cultivadas (sequía agrícola). Ello se traduce luego en pérdidas económicas e impactos negativos en el bienestar [7 - 9]. A lo largo de los años, y a través de casos estudios, han sido propuestos y validados varios índices de sequía obtenidas a partir del análisis de imágenes de satélite. Estos tienen la ventaja de poder brindar una perspectiva holística e integral de la sequía sobre áreas extensas. Destacan el Índice de Vegetación de Diferencia Normalizada (NDVI) y el Índice de Condición de la Vegetación (ICV) [10], que han demostrado su utilidad para evaluar la intensidad, la duración y el impacto de la sequía a nivel regional o global [10]. En particular, el ICV ha sido empleado para el monitoreo del impacto de eventos de sequía meteorológica a gran escala y sequía agrícola, mostrando una fuerte correlación con el rendimiento de los cultivos y superficie cosechada [10 - 13].

En el presente trabajo se evalúa el potencial del ICV como índice para identificar y monitorear eventos de sequía agrícola, tomando como área de estudio las zonas agrícolas de Piura (Valles Chira, Piura y parte del valle Chamaya). Los resultados del análisis temporal y espacial de dicho índice son contrastados con los datos estadísticos del Ministerio de Agricultura y Riego (MINAGRI) acerca de las superficies cosechadas. Estos resultados contribuyen a los esfuerzos del Observatorio Nacional de Sequía - plataforma interinstitucional liderada por la Autoridad Nacional del Agua (ANA) hacia lograr mayores capacidades para el monitoreo, prevención y mitigación de eventos de sequía.

\section{2 Área de estudio}

El área de estudio corresponde a las áreas agrícolas de la región Piura, tanto por secano como por regadío (longitud: $81.5^{\circ} \mathrm{W}$ a $79^{\circ} \mathrm{W}$; latitud: $4^{\circ} \mathrm{S}$ a $6.4^{\circ} \mathrm{S}$ ) (ver figura 1 ). En cuanto a superficies, $904.30 \mathrm{~km}^{2}$ corresponde a agricultura por secano, mientras que el de regadío cubre los 2,255.66 km². 


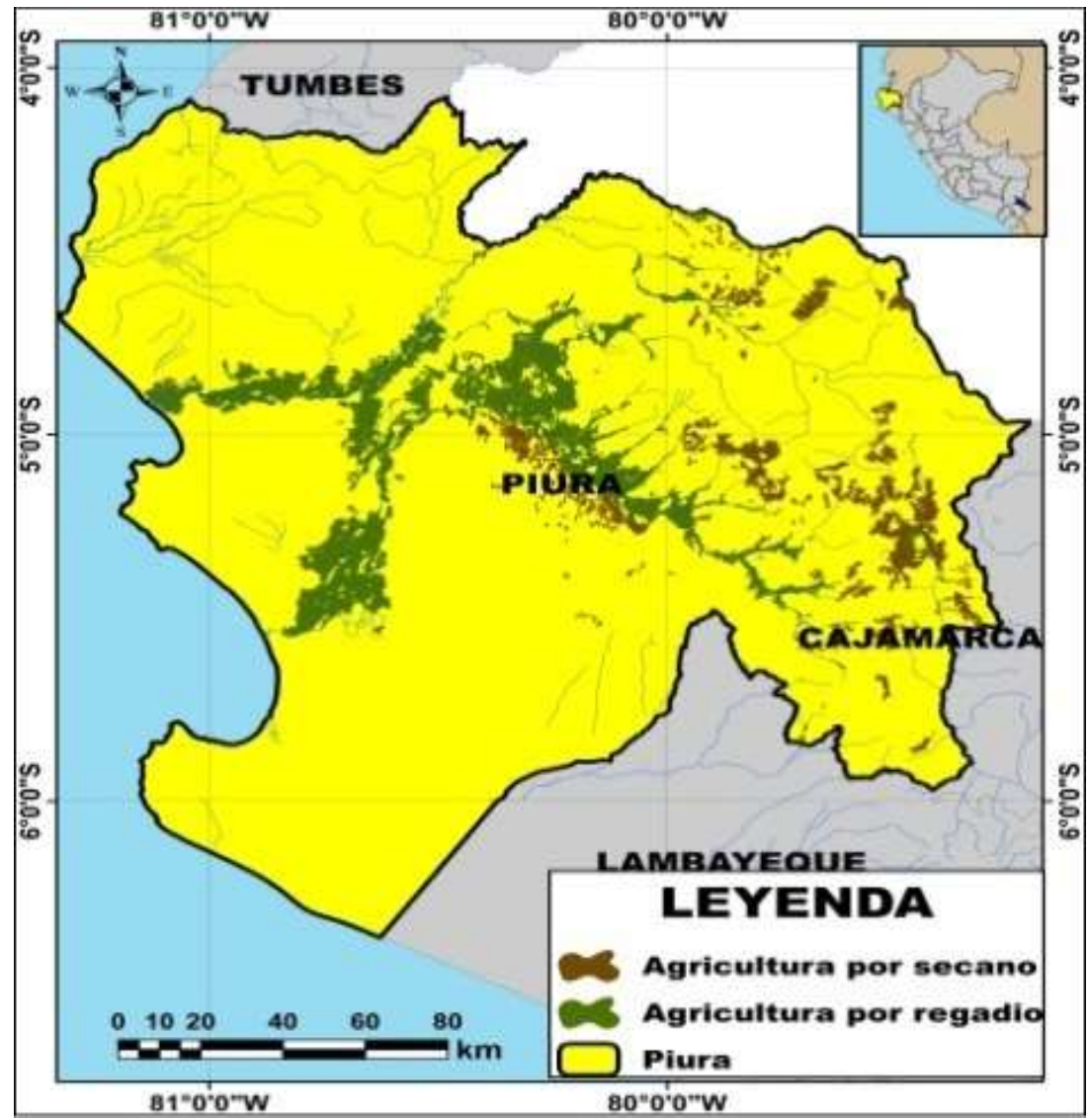

Figura 1: Área de estudio.

El clima de la región Piura es diversificado gracias a la amplia gama de pisos altitudinales y microclimas [5]. Transita de un régimen hiperárido y árido en la costa, caracterizado por una alta evapotranspiración y escasas lluvias (salvo durante los períodos de ocurrencia del Fenómeno El Niño), en el régimen semiárido tienen una precipitación anual de $300-400 \mathrm{~mm}$ a $700-800 \mathrm{~mm}$ en verano y de 200-250 mm a 450-500 mm en invierno (variación anual de precipitación es de 25-50\%), es posible el pastoreo y agricultura de regadío, aunque con gran variabilidad en las producciones, el índice de aridez de 0,20 a 0,50 [14], en el régimen sub-húmedo seco tiene una variabilidad interanual de precipitación menor a $25 \%$ y la agricultura puede desarrollarse de manera regular, donde el índice de aridez varia de 0,5 a 0,65 (tabla 1) [14]. También en la región se presentan años secos que originan sequía, generando necesidades vitales de la población, desocupación y fuerte migración del campo hacia la ciudad, pérdidas de cultivos instalados y no instalados, disminución de los hatos ganaderos por presencia de enfermedades como la enterotoxemia y también desertificación por la escasez o falta de agua [5].
Las sequías y las heladas son fenómenos meteorológicos que vienen afectando principalmente a las provincias de Ayabaca, Huancabamba, Morropón, Sullana (Lancones) y Piura. Estos fenómenos han ocasionado la pérdida de miles de hectáreas de cultivos instalados 0 dejadas de instalar,

Tabla 1: Clasificación del régimen de aridez según la Convención de las Naciones Unidas de Lucha contra la Desertificación (CLD) [15]. Teniendo en cuenta que; Ia (Índices aridez), $\boldsymbol{P}_{\boldsymbol{a}}$ (Precipitación anual), $\boldsymbol{E T}_{\mathbf{0}}$ (Evapotranspiración de referencia anual).

\begin{tabular}{|l|l|r|}
\hline & Categorías & $\begin{array}{r}\text { Índice de aridez } \\
\left(\boldsymbol{I} \boldsymbol{a}=\boldsymbol{P}_{\boldsymbol{a}} \boldsymbol{E} \boldsymbol{E}_{\mathbf{0}}\right)\end{array}$ \\
\hline & Hiperarida & $<0,05$ \\
\hline \multirow{2}{*}{ Źrida } & Árida & 0,05 a 0,20 \\
\cline { 2 - 3 } & Semiárida & 0,20 a 0,5 \\
\cline { 2 - 3 } & Subhúmeda Seca & 0,5 a 0,65 \\
\hline \multirow{2}{*}{} & Subhúmeda & 0,65 a 1,0 \\
& Húmeda & $>1,0$ \\
\hline & Húmeda & \\
\hline
\end{tabular}




\section{Metodología}

\subsection{Datos}

En este trabajo se utiliza el producto NDVI mensual (MOD13A3) del sensor MODIS a bordo del satélite TERRA se obtiene de The Application for Extracting and Exploring Analysis Ready Samples (AppEEARS). Este tiene una resolución espacial de $1 \mathrm{~km}$ y se analizó el período comprendido entre febrero 2000 a diciembre 2017. El producto NDVI es uno de los índices de vegetación que se pueden obtener utilizando las bandas infrarrojo cercano (NIR) y rojo (R). EI NDVI es un factor que se utiliza para vigilar la sequía agrícola [16,17].

La información histórica de las superficies cosechadas y producción de la región Piura fue recabada del portal MINAGRI. Donde se señalan los años 2004, 2011 y 2014 como periodos de ocurrencia de sequía, que se ve reflejado en caídas abruptas en la serie de tiempo de superficie cosechada y producción, y se muestra en línea punteada color rojo, una línea referencial que indica la evolución que se esperaba en esos años en caso no hubieran ocurrido eventos de sequía, esto permite visualizar mejor el inicio, duración y tiempo de recuperación (ver Figura 2) [6].
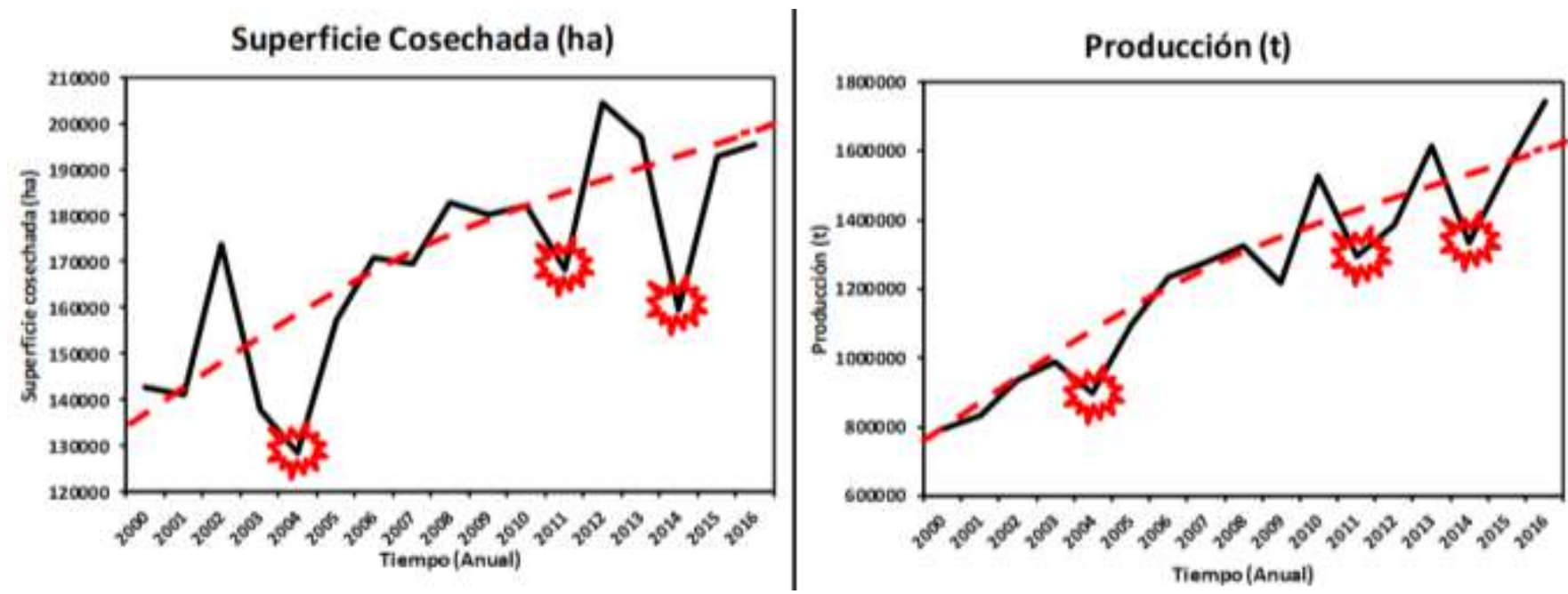

Figura 2: Serie de tiempo de la superficie cosechada y la producción para la región Piura [16]. La línea referencial que indica la evolución que se esperaba. Los años de sequía están señalados en rojo.

\subsection{Procesamiento}

En la tabla 2, se muestra la información de control de calidad realizado a los datos producto NDVI durante el periodo 2000 al 2017. Donde el 99,2\% de pixeles del NDVI son de buena calidad y el $0,8 \%$ de pixeles producido, pero con alta probabilidad de nube.

Tabla 2: Frecuencia de calidad del producto NDVI durante el periodo febrero 2000 al diciembre 2017.

\begin{tabular}{|c|r|r|l|r|}
\hline Bits & & Valor & Descripción & NDVI \\
\hline \multirow{3}{*}{$0-1$} & \multirow{3}{*}{ QA } & 00 & VI producido con buena calidad. & $99,2 \%$ \\
\cline { 3 - 4 } & 01 & VI producido, pero chequear con otro valor de calidad. & $0 \%$ \\
\cline { 2 - 4 } & 10 & Pixel producido, pero con más probabilidad con nube. & $0,8 \%$ \\
\cline { 2 - 4 } & 11 & Pixel no producido por otras razones de efectos de nubes. & $0 \%$ \\
\hline
\end{tabular}

\subsection{Calculo ICV}

Para las regiones con vegetación, los cambios en el NDVI relacionados con el clima son más pequeños que los relacionados con el ecosistema y los impactos de la sequía sobre la vegetación no pueden ser fácilmente detectados a partir de datos del NDVI directamente [18]. Kogan (1995), desarrolló el índice de condición de la vegetación (ICV) para controlar las diferencias locales en la productividad de los ecosistemas [19]. El ICV es una normalización basada en píxeles del NDVI y es un indicador más sensible a variaciones climáticas para el caso de áreas con vegetación vigorosa es 
decir, NDVI $\approx 1$ [18].

El ICV se define mediante la siguiente fórmula (1):

$$
I C V=100 x \frac{N D V I-N D V I_{\min }}{N D V I_{\max }-N D V I_{\min }}
$$

Los valores de los píxeles del NDVI, NDVI max y $N D V I_{\min }$ son, respectivamente, el máximo y el mínimo del NDVI. El ICV varía de 0 a 100, que corresponde a los cambios en la condición de la vegetación de extremadamente desfavorable a óptima. En caso de un mes extremadamente seco, el estado de la vegetación es escaso y el $I C V \approx 0$. La vegetación refleja un estado adecuado cuando el $I C V \geq 50$. Para diferentes clases de Sequia los valores de ICV se presentan en la Tabla 3 . En condiciones óptimas de la vegetación, el $I C V \approx 100$.

Tabla 3: Esquema de clasificación ICV [18].

\begin{tabular}{|c|c|}
\hline $\begin{array}{c}\text { Esquema de } \\
\text { Clasificación } \\
\text { de Sequía }\end{array}$ & ICV \\
\hline Sequía Extrema & $<10$ \\
\hline Sequía Severa & $<20$ \\
\hline Sequía Moderada & $<30$ \\
\hline Sequía Leve & $<40$ \\
\hline No hay Sequia & $>40 \square$ \\
\hline
\end{tabular}

Para el cálculo del ICV, se trabajó con los pixeles de buena calidad para luego multiplicar por el factor escala de 0.0001 al producto del NDVI. El ICV es una normalización basada en píxeles del NDVI, el ICV se define mediante la fórmula (1), posteriormente se procede con la validación de las áreas agrícolas por secano y por regadío de la región Piura. La investigación tiene como objetivo analizar el índice de condición de la vegetación a partir del producto NDVI, durante el periodo 2000 al 2017 sobre las áreas agrícolas por secano y por regadío de la región Piura. El diagrama de flujo de la metodología se presenta en la Figura 3.

\section{Resultados}

En la presente investigación, la fuerte sequía experimentada en los años 2004, 2011 y 2014 se visualizan los patrones espaciales de sequía anualmente basado en el ICV en las áreas agrícolas por secano de la región Piura, en el periodo 2000 febrero al 2017 diciembre (Figura 4). Donde se muestra para las áreas agrícolas por secano, donde el $+5 \%$ de áreas en condiciones de sequía extrema $y+16 \%$ de áreas en condiciones de sequía severa durante el $2004,+7.5 \%$ de áreas en condiciones de sequía extrema y el $12 \%$ de áreas en condiciones de sequía severa durante el $2007,+1.5 \%$ de áreas en condición de sequía extrema y $+14 \%$ de áreas en condición de sequía severa durante el 2011 y el $+18 \%$ de áreas en condición de sequía extrema y +3 \% de áreas en condición de sequía severa durante el 2014.

En la figura 5 se muestra los patrones espaciales de sequía anualmente basado en el ICV, para las áreas agrícolas por regadío de la región Piura, el $+11.3 \%$ de áreas en condición de sequía extrema, $32.8 \%$ de áreas en condición de sequía severa y $24 \%$ de áreas en condición de sequía moderada durante el 2004 , el $3.7 \%$ de áreas en condición de sequía extrema, el $24 \%$ de áreas en condición de sequía severa y el $27 \%$ de áreas en condición de sequía moderada durante el $2005,+4.7 \%$ de áreas en condición de sequía extrema y $+12 \%$ de áreas en condición de sequía severa y $+21 \%$ de áreas en condición de sequía moderada durante el 2007, +1 $\%$ de áreas en condición de sequía extrema, $+4.6 \%$ de áreas en condición de sequía severa y $+11.5 \%$ de áreas en condición de sequía moderada durante el 2011 y $+5.6 \%$ de áreas en condición de sequía extrema, $+13 \%$ de áreas en condición de sequía severa y $+18 \%$ de áreas en condición de sequía moderada durante el 2014.

En la región de Piura se realizaron campañas agrícolas el 2003 y 2004 donde los impactos de la sequía han ocasionado pérdidas considerables, 
principalmente en las provincias de Morropón, Ayabaca y Huancabamba y en segundo orden en las provincias de la Costa como Piura, Sullana, Sechura, Paita y Talara durante los años 2003, 2004 y 2005, por lo que se presentó la pérdida de miles de hectáreas de cultivos instalados o dejadas de instalar; pérdida de ganado debido a la escasez de pastos y que ha propiciado la migración del poblador rural a las ciudades urbano marginales, según reportes de la Dirección Regional de Agricultura entre enero y febrero del 2004 por efecto de la sequía se han perdido $9028 \mathrm{Ha}$ de Cultivos instalados, valorizados en \$ 23 856- 301.43. En el período octubre 2004 a febrero 2005, por efectos de heladas y sequía, se presentaron daños en los cultivos, pastos y ganadería, por un valor de $\$ 151$ 882780.5 (Tabla 4) [5].

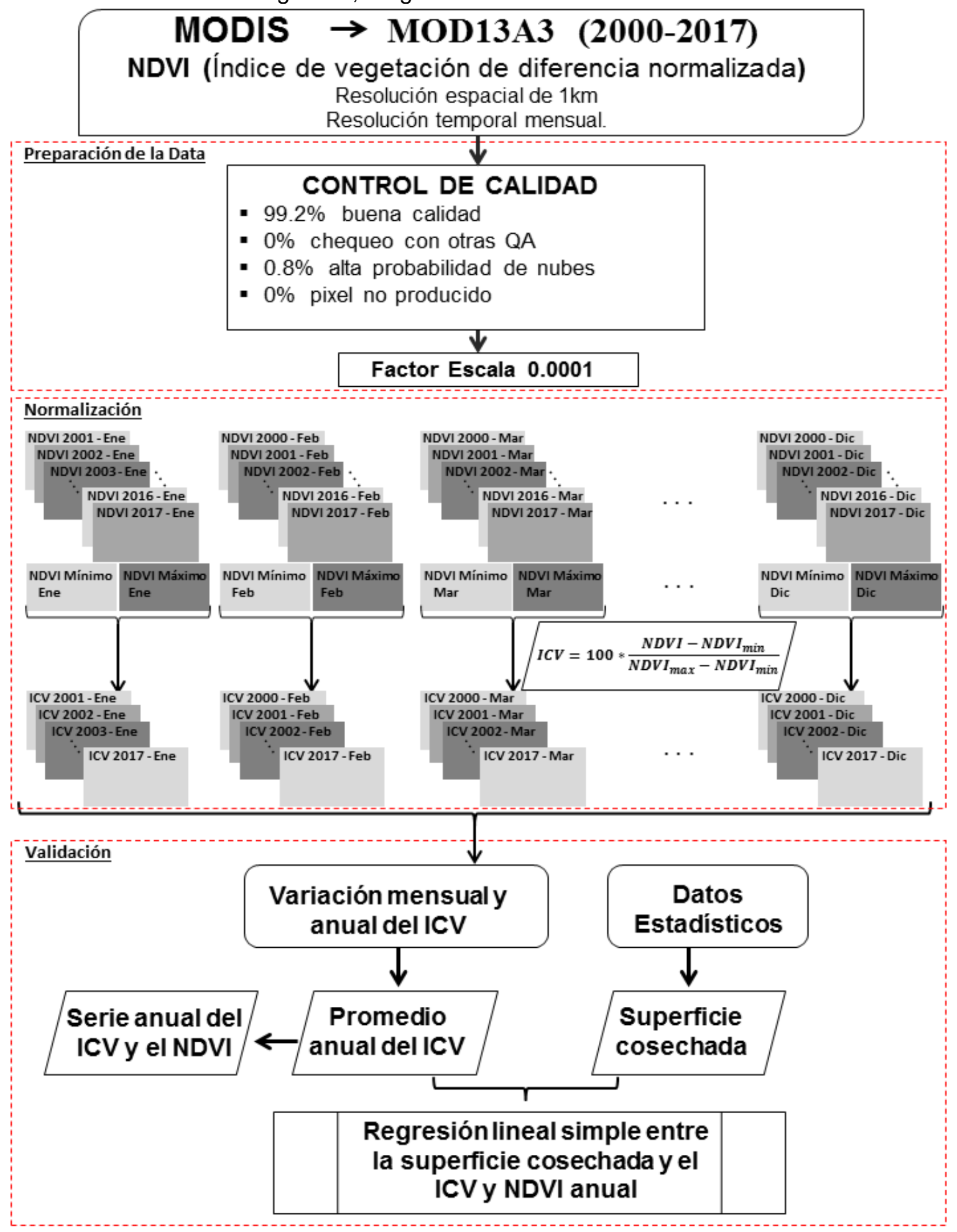

Figura 3. Esquema de la metodología. 


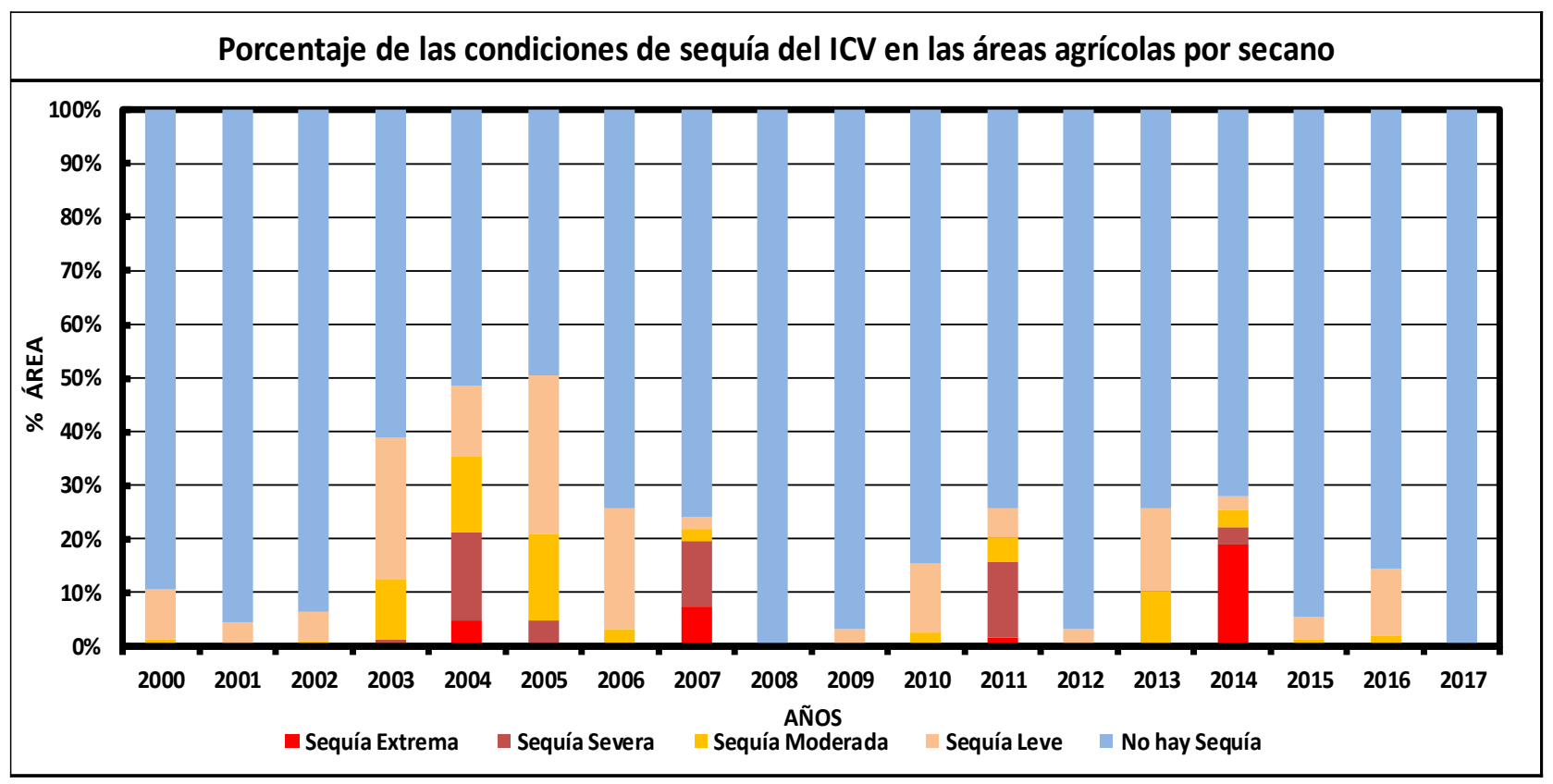

Figura 4: Los patrones espaciales de sequía basados en el ICV en las áreas agrícolas por secano de la región de Piura, en el periodo 2000 febrero al 2017 diciembre.

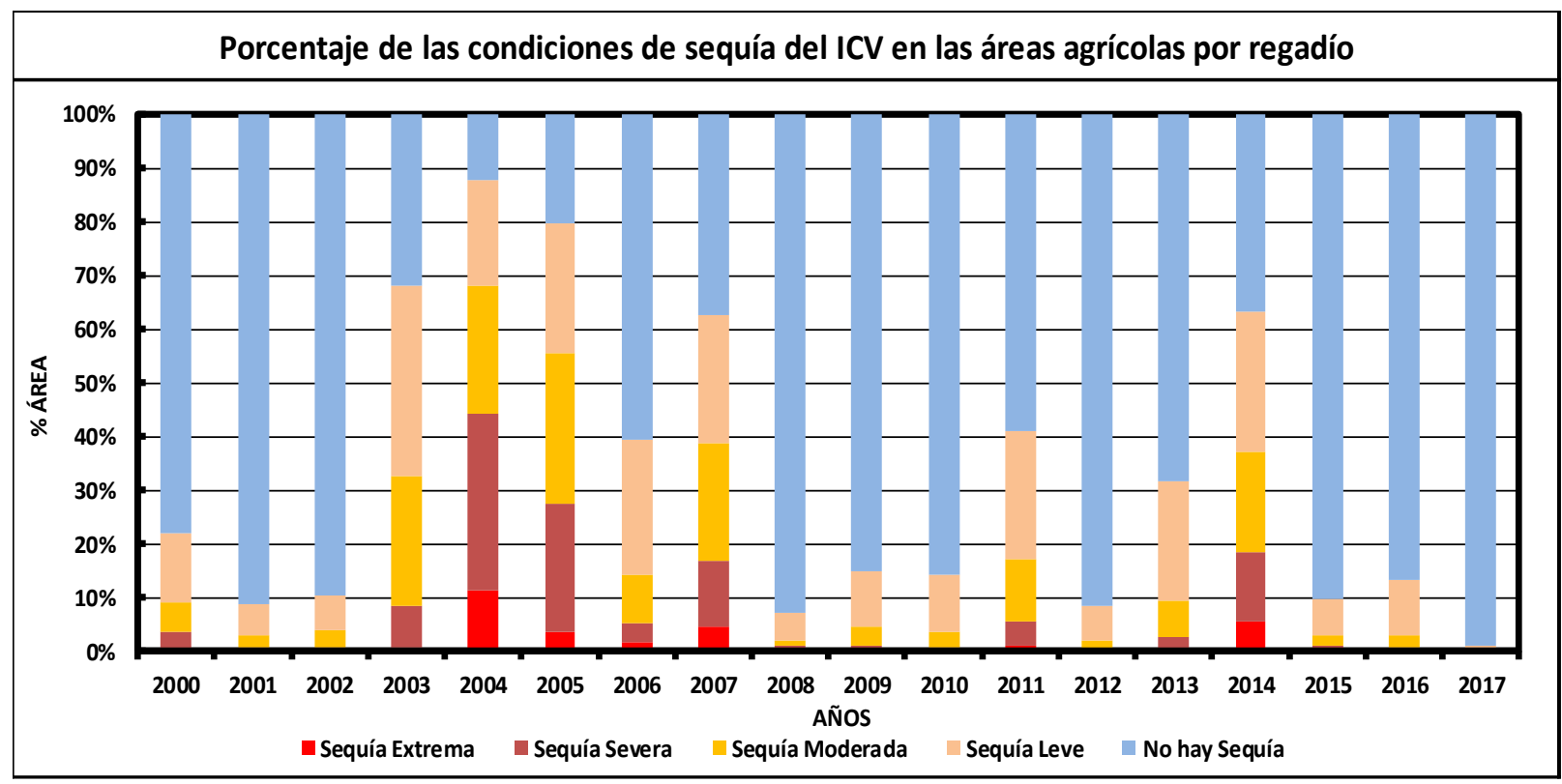

Figura 5: Los patrones espaciales de sequía basados en el ICV en las áreas agrícolas por regadío de la región de Piura, en el periodo 2000 febrero al 2017 diciembre.

Tabla 4. Áreas perdidas y afectadas por sequía en la campaña agrícola 2003/2004 [5].

\begin{tabular}{|l|r|r|r|r|}
\hline \multirow{2}{*}{ Agencia Agraria } & \multicolumn{4}{|c|}{ Sequía } \\
\cline { 2 - 5 } & Área Afectada (Has) & Valorización en Nuevos Soles & Área Perdida (Has) & Valorización \$ \\
\hline Ayabaca & 4707 & 1690801,47 & 2793 & 7432443,36 \\
\hline Morropón & 395,4 & 406131,16 & 420 & 1117233,6 \\
\hline Huancabamba & 6510 & 2509214,40 & 5625 & 14806494 \\
\hline Sullana & 0 & 0 & 190 & 500130,464 \\
\hline Total & 11612,40 & 4606147,03 & 9028 & 23856301,4 \\
\hline
\end{tabular}


En el 2011, fueron más de 50 mil hectáreas afectadas en las provincias de Ayabaca, Huancabamba y Morropón y los distritos de Lancones, Las Lomas y Tambo Grande [20]. En setiembre del 2013 a marzo del 2014 ante el déficit hídrico y la falta de lluvia en Chulucanas, Ayabaca, Huancabamba y Morropón la sequía afectó 3 mil hectáreas de cultivos y 3016 hectáreas afectadas por falta de lluvia y se dejaron de sembrar 22 mil hectáreas con cultivos de arroz, frejol y frutales de estas 1849 hectáreas se vieron afectados por la sequía, por lo cual se han perdido $\$ 65,6$ millones en cultivos por la sequía y en el sector ganadero la perdida suma \$ 5248000.00 en ello involucra a 5 mil cabezas de ganado vacuno que fueron afectados por falta de agua y pasto (mil murieron y cuatro mil restantes fueron rematadas) [21].

\section{Conclusiones}

El patrón espacial del ICV en la presente investigación fue determinado por el producto NDVI del sensor MODIS. EI ICV es el estado de crecimiento de la vegetación en el proceso de la sequía y es favorable para monitorear la sequía agrícola, el resultado fue consistente con la sequía ocurrida en los años 2004, 2007, 2011 y 2014 en las áreas agrícolas por secano y por regadío de la región Piura. El promedio anual del NDVI y el ICV de las áreas agrícolas son reflejados con los reportes de la campaña agrícola realizados por el gobierno regional de Piura y a la información histórica del MINAGRI.

El año 2017 donde el ICV tanto en las áreas agrícolas por secano como por regadío muestra que no hay sequía debido a la ocurrencia del fenómeno El Niño.

\section{Agradecimientos}

G. I. C. D. agradece al Programa Cátedra CONCYTEC por el soporte financiero de la beca de Maestría en Física y al proyecto PEER: "Strengthening resilience of Andean river basin headwaters facing Global change" por el financiamiento del trabajo de campo realizado en Piura y la participación en diversos eventos ya sea en forma oral o poster.

\section{Referencias}

[1] Organización Meteorológica Mundial (OMM), 1990. Glossary of terms used in agrometeorology. CAGM No. 40. WMO/TDNo. $391 . \quad$ Geneva. http://www.wmo.int/pages/prog/wcp/agm/pub lications/cagm reports.php (revisado 01/10/2015)

[2] D. A. Wilhite and M. H. Glantz, Water International 10 (1985) 111-120.

[3] M.S. Zhao, S.W. Running, Science 329 (2010) 940-943.
[4] INDECI, "Plan Nacional de Gestión del Riesgo de Desastres- PLANAGERD 2014 2021" (Perú, 2014).

[5] PRPAD. Plan Regional de Prevención y Atención de Desastres de la Región Piura, (Región de Piura 2005) p. 64.

[6] http://frenteweb.minagri.gob.pe/sisca/?mod= consulta cult (Fecha de acceso 06/01/2018).

[7] AMS American Meteorological Society 85, (2004) 771-773.

https://www.highbeam.com/doc/1P3654400081.html

https://www.ametsoc.org/ams/index.cfm/abo ut-ams/ams-statements/archive-statementsof- the-ams/meteorological-drought/ Fecha de acceso: 30 de enero de 2017.

[8] D. Wilhite y M. Glantz. Water International 10 (1985) 111-120.

[9] R. Heim. Bulletin of the American Meteorological Society 83 (2002) 1149-1166.

[10] W. Liu, F. Kogan, International Journal of Remote Sensing 17 (1996) 2761-2782.

[11] L. Unganai, F. Kogan, Remote Sensing of Environment 63 (1998) 219-232.

[12] F.N., Kogan, B., Yang, G., Wei, P., Zhiyuan, J., Xianfeng, International Journal of Remote Sensing 26 (2005) 2325-2336.

[13] S.M., Vicente-Serrano, Evaluating the impact of drought using remote sensing in a Mediterranean, semi-arid region. Natural Hazards 40 (2007) 173-208.

[14] MINAM, Mapas de tierras secas del Perú (2012). p 32.

[15] MINAM. La Desertificación en el Perú. Cuarta comunidad Nacional del Perú a la Convención de Lucha contra la Desertificación y la Sequía. Lima. (2011), p. 74.

[16] W.T., Liu, R.I.N., Juarez, International Journal of Remote Sensing 22 (2001) 3483-3501.

[17] J., Wang, K.P., Price, P.M., Rich. International Journal of Remote Sensing 22 (2001) 38273844.

[18] L., Du, Q., Tian, T., Yu, Q., Meng, T., Jancso, P., Udvardy, Y., Huang. International Journal of Applied Earth Observation and Geoinformation 23 (2013) 245-253. 
[19] F.N., Kogan. Bulletin of the American Meteorological Society 76 (1995b) 655-668.

[20] http://morroponpiuranoticias.blogspot.pe/2011/03/sequia-enpiura.html (Fecha de acceso 08/01/2018).
[21] http://larepublica.pe/economia/773591perdida-por-sequia-en-piura-suma-mas-de-s20-millones (Fecha de acceso 08/01/2018).

E-mail: gisellcarbajal@gmail.com 